\title{
Alteration of renal cyclooxygenase expression due to partial unilateral ureteral obstruction in neonatal
}

\author{
Zhi Qin Li, MD; ; Yi Zhang, MD, PhD; ${ }^{\dagger}$ Qi Li, MD; Shu Huan Wu, MD; Chang Yu Sun, MD; Zu Jiang Yu, MD*
}

*Infectious Disease Department, The First Affiliated Hospital of Zhengzhou University, China; ${ }^{\circ}$ Biological Cells Treatment Center, The First Affiliated Hospital of Zhengzhou University, China; ${ }^{ \pm}$Urology Department of The First Affiliated Hospital of Zhengzhou University, China

Cite as: Can Urol Assoc J 2013;7:E150-E155. http://dx.doi.org/10.5489/cuaj.11163. Epub 2012 March 2.

\section{Abstract}

Introduction: Impaired renal water handling in response to neonatally-induced partial unilateral ureteral obstruction (PUUO) may be associated with altered expression of cyclooxygenase (COX). The purpose of the present study was to examine whether long-term PUUO induced at birth was associated with changes of COX-2.

Methods: Rats were subjected to PUUO $(n=14)$ or a sham operation $(n=12)$ within the first 48 hours of life. The rats were divided into 4 groups: (1) PUUO at 9 weeks $(n=7)$; (2) the sham operation at 9 weeks $(n=6)$; (3) PUUO at 15 weeks $(n=7)$; and (4) the sham operation at 15 weeks $(n=6)$. Urine and blood samples were collected before sacrificing the animals. Plasma potassium, creatinine and urea, as well as the osmolality and sodium of plasma and urine were tested in each sample. The expression of renal COX-1 and COX-2 was examined at 9 and 15 weeks in rats with neonatallyinduced PUUO within the first 48 hours of life by immunoblotting and immunocytochemistry.

Results: PUUO caused a marked decrease in urine osmolality and a significant increase in urinary sodium of the obstructed kidney compared with the sham-operated kidney at 9 and 15 weeks. Immunoblotting analysis showed that an abundance of COX-2 in the obstructed kidney significantly increased compared with the non-obstructed kidney and sham-operated kidney at 9 weeks $(p<0.05)$ and 15 weeks $(p<0.05)$ in rats with PUUO. In contrast, COX-1 abundance in the obstructed kidney was similar to that in the non-obstructed kidney. Immunocytochemistry confirmed these findings.

Conclusion: Renal COX-2 expression in the obstructed kidney is significantly altered in response to neonatally-induced PUUO. A marked increase in COX-2 indicates that it may be an important factor in reducing renal handling of sodium and water in response to PUUO.

\section{Introduction}

Congenital obstructive nephropathy is the primary cause of renal insufficiency in children. ${ }^{1}$ Congenital ureteral obstruction is distinguished by the profound impairment of kidney functions. ${ }^{2}$ Previous studies have shown that unilateral ureteral complete obstruction in adult rats caused impairment of urinary concentrating ability. ${ }^{3,4}$ However, neonatal partial unilateral ureteral obstruction (PUUO) as an experimental model for congenital obstructive nephropathy is clinically much more common than complete obstruction. Wen and colleagues demonstrated that PUUO induced neonatally in rats was associated with the development of progressive hydronephrosis. ${ }^{5}$ The rat was chosen because obstruction induced shortly after birth simulates obstruction in the last trimester in humans. In the pediatric population, obstruction at the pelvic-ureteral junction is mostly partial and congenital. Furthermore, with rats, we can obtain a sufficient number of obstructed animals to cover the large variety of responses to obstruction seen in clinical and experimental materials with respect to severity and changes in renal morphology and function. Using this animal model, some researchers have concluded that major sodium transporters and aquaporins (AQPs) in the obstructed kidney were down-regulated in response to neonatally-induced PUUO. This indicates that these transporters may play a crucial role in the persistent reduction of renal handling of sodium and water in response to PUUO. ${ }^{6}$ The mechanisms responsible for the dysregulation of these transport proteins and channels remain unclear.

The mammalian kidney is one of the most active prostaglandin (PG)-producing tissues and PGE2 is the quantitatively dominant prostanoid. PGE2 regulates and modulates renal hemodynamics and tubular water and salt transport. ${ }^{7}$ Cyclooxygenase (COX) is the major rate-limiting enzyme in the cascade leading to synthesis of PG from arachidonic acid. Two isoforms are recognized: constitutive COX-1 and inducible COX-2. The COX-1 isoform is believed to 
be constitutively expressed in most cells and involved in the maintenance of various physiological functions; ${ }^{8}$ COX-2 is undetectable in most tissues. In contrast, COX-2 is constitutively expressed in the kidney. ${ }^{7}$ Previous studies have demonstrated that COX-2 expression increased in the obstructed kidneys in response to 24-hour unilateral ureteral obstruction (UUO) ${ }_{1}^{9}$ ureteral obstruction of a solitary kidney ${ }^{10}$ and in response to bilateral ureteral obstruction (BUO). ${ }^{11}$ Moreover, it was recently demonstrated that acute BUO leads to marked upregulation of COX-2 in inner medulla; selective COX-2 inhibition prevents dysregulation of AQP2 in response to $\mathrm{BUO}$, indicating that COX-2 may be an important factor contributing to the impaired renal water and sodium handling in response to BUO. ${ }^{12}$ Thus, it is speculated that impaired renal water handling in response to neonatally-induced PUUO may be associated with altered expression of COX-2. In the present study, we examine whether long-term PUUO induced at birth affects the abundance of renal cyclooxygenase.

\section{Methods}

\section{Experimental animals}

Experiments were performed using 26 male Wistar rats with an average weight of 6 to $8 \mathrm{~g}$. Rats were subjected to PUUO $(n=14)$ or a sham operation $(n=12)$ within the first 48 hours of life. PUUO was created using a modification of the UIm and Miller's technique, which results in the development of severe hydronephrosis. ${ }^{13}$ Briefly, the newborn rats were anesthetized with ether and placed on a heated table. The left ureter was exposed through a midline incision. PUUO was created by embedding two thirds of the left ureter in a muscle tunnel of the underlying psoas muscle. ${ }^{6,14}$ The sham group was prepared by laparotomy and mobilization of the left ureter. After surgery, rats were kept in an incubator at $28^{\circ} \mathrm{C}$ until totally awake, and then returned to regular animal units with their mother. After 4 weeks, the rats were separated from their mother and housed 2 per cage. During the experiments the rats were maintained at controlled temperatures $\left(22\right.$ to $\left.24^{\circ} \mathrm{C}\right)$ and moisture $(60 \%)$ with a 12 -hour artificial light-dark cycle. The rats were fed a standard rodent diet and tap water.

The rats were divided into 4 groups: (1) PUUO at 9 weeks $(n=7) ;(2)$ the sham operation at 9 weeks $(n=6) ;(3)$ PUUO at 15 weeks $(n=7)$; and (4) the sham operation at 15 weeks $(n=6)$. The harvested kidneys were rapidly frozen in the liquid nitrogen and kept at $-80^{\circ} \mathrm{C}$ until assayed or rapidly put into formalin for immunohistochemistry.

All procedures conformed to the Chinese national guidelines for the caring and handling of animals. The animal protocol was approved by the Board of Zhengzhou University.

\section{Urine and blood sampling}

To collect urine, both ureters were exposed and catheterized through a midline incision as described by Topcu and colleagues. ${ }^{15}$ Before sacrificing the animals, we drew about $2 \mathrm{~mL}$ of artery blood from the abdominal aorta in gas-tight syringes; both kidneys were then quickly removed for immunoblotting. The blood was centrifuged for 15 minutes at $4000 \mathrm{~g}$ to remove the blood cells, and the plasma was subsequently analyzed for sodium, potassium, creatinine and urea (Hitachi 7600-020 automatic biochemical analyzer, Hitachi High-Technologies, Tokyo, Japan). The osmolality of plasma and urine was measured by freezing-point depression (Advanced Instruments Multi-Sample Osmometer, Model 3900, Norwood, MA). Urinary sodium was measured by a 7600-020 automatic biochemical analyzer (Hitachi HighTechnologies, Tokyo, Japan) for each sample.

\section{Electrophoresis and immunoblotting}

Samples of membrane fractions from whole kidneys were run on $12 \%$ or $9 \%$ SDS-polyacrylamide minigels (Mini Protean III, Bio-Rad Laboratories, Inc., China). For each gel, an identical gel was run in parallel and subjected to Coomassie blue staining. The Coomassie-stained gel was used to verify identical loading or to allow for potential correction for minor differences in loading after scanning and densitometry of major bands. The other gel was subjected to Western blotting analysis. After transfer by electroelution to nitrocellulose membranes, blots were blocked with $5 \%$ milk in PBS-T $\left(80 \mathrm{mM} \mathrm{Na}_{2} \mathrm{HPO}_{4^{\prime}} 20 \mathrm{mM} \mathrm{NaH}_{2} \mathrm{PO}_{4^{\prime}}\right.$ $100 \mathrm{mM} \mathrm{NaCl}, 0.1 \%$ Tween 20, pH 7.5) for 1 hour and incubated with primary antibodies overnight at $4^{\circ} \mathrm{C}$. After being washed with PBS-T, the blots were incubated with horseradish peroxidase-conjugated secondary antibody (1:8000; Zhongshan Biotechnology, Beijing, China) for 1 hour. After a final washing as above, antibody binding was visualized using the enhanced chemiluminescence (ECL) system (Amersham Laboratories, UK). ECL films with bands within the linear range were scanned using ImageJ software. The labelling density was corrected by densitometry of the Coomassie blue-stained gels.

\section{Immunocytochemistry}

The kidneys from the PUUO rats and the sham-operated rats were fixed by retrograde perfusion via the abdominal aorta with $3 \%$ paraformaldehyde, in $0.1 \mathrm{M}$ cacodylate buffer $\mathrm{pH}$ 7.4. For immunoperoxidase microscopy, kidney blocks containing all kidney zones were dehydrated and embedded in paraffin and 4- $\mu \mathrm{m}$ sections were made. After blocking the endogenous peroxidase reaction with $3 \% \mathrm{H}_{2} \mathrm{O}_{2}$ and citrate antigen hot fix (0.01M, pH 6.0), rabbit anti COX-1 and COX-2 
Li et al.

polyclonal antibody (Santa Cruz Biotechnology, Santa Cruz, $\mathrm{CA}$ were allowed to react on serial sections and incubated overnight at $4^{\circ} \mathrm{C}$. The dilution of COX- 1 and COX-2 were $1: 200$ and $1: 200$, respectively. Biotin-labelled goat anti-rabbit $\lg \mathrm{G}$ was added to the sections and incubated at $37^{\circ} \mathrm{C}$ for 30 minutes. SP complex was added and then DAB- $\mathrm{H}_{2} \mathrm{O}_{2}$ was used for the colour reaction. PBS $(0.01 \mathrm{M}, \mathrm{pH} 7.4)$ without primary antibody was applied for the negative control.

\section{Statistical analysis}

All values are presented in the text as means \pm standard error of the mean (SEM). Unpaired and paired Student $t$-tests were used for comparisons. The $p$ values less than 0.05 were considered statistically significant.

\section{Results}

PUUO associated with impaired urinary concentration of the obstructed kidney

To examine the effects of PUUO on renal water handling, osmolality and sodium, potassium, creatinine, and urea concentration in plasma and urine were measured from obstructed and non-obstructed kidneys (Table 1). The urine osmolality of the obstructed kidney was markedly reduced at 9 weeks compared with the sham-operated controls (398 \pm 37 vs. $807 \pm 184 \mathrm{mosmol} / \mathrm{kg}, p<0.05)$, and remained low after 15 weeks of PUUO (401 \pm 47 vs. $625 \pm 89$ mos$\mathrm{mol} / \mathrm{kg}, p<0.05)$. Urine osmolality did not decrease in the nonobstructed kidneys either at 9 or at 15 weeks of PUUO. There was a significant increase in urinary sodium in the obstructed kidney compared with the sham-operated con- trols at 9 weeks $(77.9 \pm 11.5$ vs. $29.1 \pm 4.9 \mathrm{mM}, p<0.05$, respectively), which persisted 15 weeks after onset of PUUO $(91.8 \pm 10.9$ vs. $15.2 \pm 2.1 \mathrm{mM}, p<0.05$, respectively). Compared with the nonobstructed kidneys, urinary sodium also increased in the obstructed kidneys at 9 and at 15 weeks of PUUO $(77.9 \pm 11.5$ vs. $37.2 \pm 10.1 \mathrm{mM} ; 91.8 \pm 10.9$ vs. $22.8 \pm 5.6 \mathrm{mM}, p<0.05$, respectively).

\section{Expression of COX-1 and COX-2 in response to PUUO}

We examined the expression of COX-1 and COX-2 of the whole kidney. COX-1 was localized to the connecting tubule and cortical collecting ducts (Fig. 1, panels A, B, C, $\mathrm{G}, \mathrm{H}$ and $\mathrm{I}$ ). Immunoblotting revealed that the abundance of COX-1 protein was unchanged between the obstructed and the non-obstructed kidney in response to either 9 or 15 weeks of PUUO (Table 2, Fig. 2, panels A and C).

In contrast, in PUUO at 9 and 15 weeks, COX-2 expression level was significantly increased in the obstructed kidneys ( $894 \%$ of sham level, $p<0.05 ; 902 \%$ of sham level, $p<0.05)$, whereas the expression of COX-2 in non-obstructed kidneys did not differ from that of the sham-operated controls (Table 2, Fig. 2, panels B and D). These findings were also examined by immunocytochemistry. COX-2 protein was localized to the medullary interstitial cells; there was a marked increase in the COX-2 labelling in obstructed kidneys of PUUO in the rats at 9 and 15 weeks compared with the sham-operated rats (Fig. 1, panels D, E, F, J, K and L).

\section{Discussion}

The main results of the present study demonstrated the neonatally-induced PUUO in rats caused a significant decrease in urine osmolality and increased the abundance of urinary

\begin{tabular}{|c|c|c|c|c|}
\hline & \multicolumn{2}{|c|}{9 weeks } & \multicolumn{2}{|c|}{15 weeks } \\
\hline & PUUO & Sham & PUUO & Sham \\
\hline Number & 7 & 6 & 7 & 6 \\
\hline Body weight, g & $192 \pm 8$ & $195 \pm 10$ & $364 \pm 8$ & $379 \pm 14$ \\
\hline $\mathrm{P}_{\text {osm }^{\prime}} \mathrm{mosmol} / \mathrm{kgH}_{2} \mathrm{O}$ & $298 \pm 1.1$ & $298 \pm 0.9$ & $302 \pm 1.2$ & $302 \pm 2.5$ \\
\hline $\mathrm{P}_{\mathrm{Na}^{\prime}} \mathrm{mM}$ & $136.4 \pm 1.2$ & $136 \pm 1.1$ & $140 \pm 0.9$ & $139 \pm 1.2$ \\
\hline $\mathrm{P}_{\mathrm{K}^{\prime}} \mathrm{mM}$ & $4.3 \pm 0.1$ & $4.3 \pm 0.1$ & $4.4 \pm 0.1$ & $4.4 \pm 0.1$ \\
\hline $\mathrm{P}_{\text {crea' }}, \mu \mathrm{M}$ & $7.2 \pm 0.5$ & $6.8 \pm 0.3$ & $31 \pm 1.8$ & $29 \pm 0.7$ \\
\hline $\mathrm{P}_{\text {urea }^{\prime}} \mathrm{mM}$ & $6.4 \pm 0.3$ & $5.8 \pm 0.2$ & $6.6 \pm 0.5$ & $5.6 \pm 0.3$ \\
\hline \multicolumn{5}{|l|}{$\mathrm{U}_{\mathrm{osm}^{\prime}}, \mathrm{mosmol} / \mathrm{kgH}_{2} \mathrm{O}$} \\
\hline OBS & $398 \pm 37^{a}$ & $807 \pm 184$ & $401 \pm 47^{a}$ & $625 \pm 89$ \\
\hline Non-OBS & $624 \pm 118$ & $905 \pm 215$ & $647 \pm 123$ & $635 \pm 95$ \\
\hline \multicolumn{5}{|l|}{$\mathrm{U}_{\mathrm{Na}^{\prime}}, \mathrm{mM}$} \\
\hline OBS & $77.9 \pm 11.5^{a, b}$ & $29.1 \pm 4.9$ & $91.8 \pm 10.9$ a, b & $15.2 \pm 2.1$ \\
\hline Non-OBS & $37.2 \pm 10.1$ & $26.9 \pm 3.5$ & $22.8 \pm 5.6$ & $13.4 \pm 1.3$ \\
\hline
\end{tabular}




\begin{tabular}{|c|c|c|c|}
\hline $\begin{array}{l}\text { Expression of renal } \\
\text { cyclooxygenases }\end{array}$ & OBS $(n=7)$ & Non-OBS $(n=7)$ & Sham $(n=6)$ \\
\hline \multicolumn{4}{|l|}{9 weeks } \\
\hline COX-1 & $1.19 \pm 0.09$ & $1.28 \pm 0.1$ & $1.0 \pm 0.09$ \\
\hline coX-2 & $8.94 \pm 3.14^{\mathrm{a}, \mathrm{b}}$ & $1.33 \pm 0.11$ & $1.0 \pm 0.17$ \\
\hline \multicolumn{4}{|l|}{15 weeks } \\
\hline cox-1 & $1.24 \pm 0.11$ & $0.93 \pm 0.12$ & $1.0 \pm 0.05$ \\
\hline coX-2 & $9.02 \pm 2.94^{\mathrm{a}, \mathrm{b}}$ & $1.34 \pm 0.09$ & $1.0 \pm 0.18$ \\
\hline
\end{tabular}

sodium in the obstructed kidney at 9 and 15 weeks after the onset of PUUO. Moreover, PUUO was associated with an increase in COX-2, and not COX-1 in the obstructed kidney. Immunohistochemistry confirmed an up-regulation of COX-2 in the obstructed kidneys. This is consistent with previous reports demonstrating an increase COX-2 expression in response to $\mathrm{BUO},{ }^{12}$ in response to occlusion of a solitary kidney, ${ }^{11}$ and also in kidney inner medullary (IM) of rats subjected to UUO. ${ }^{10}$

Neonatally-induced ureteral obstruction results in severe injury of the obstructed kidney. The results of the present

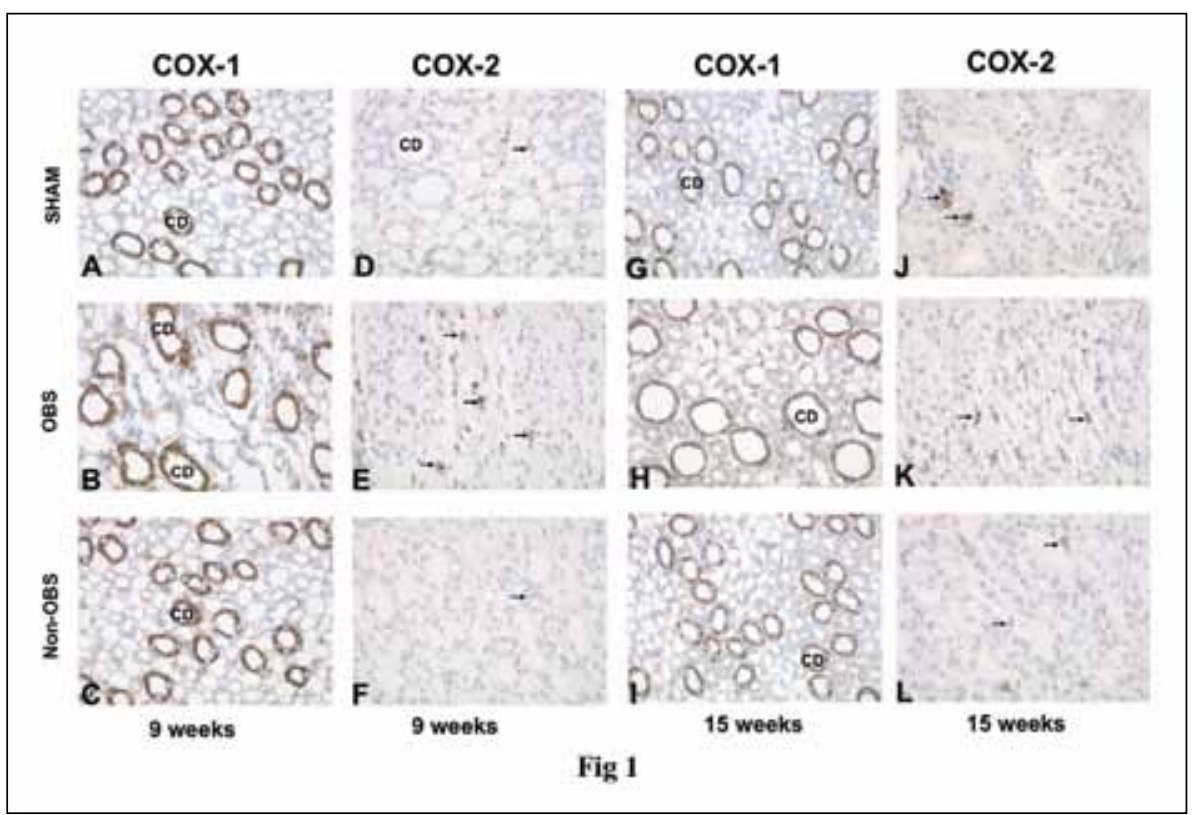

Fig. 1. Immunohistochemistry of whole kidney protein samples from obstructed (OBS) and non-obstructed kidneys (non-OBS) from PUU0-9 W and PUU0-15 W rats, and kidneys from matched sham-operated rats (SHAM). A-C: Immunohistochemistry for COX-1 in the collecting duct (CD) of OBS, Non-OBS and SHAM from 9-week-old PUUO and SHAM rats. G-I: Immunohistochemistry for COX-1 in the collecting duct (CD) of OBS, Non-OBS and SHAM from 15-week-old PUUO and SHAM rats. COX-1 labelling did not differ between OBS, Non-OBS and SHAM. D-E: Immunohistochemistry for COX-2 in the interstitial cells (filled arrows) of OBS, Non-OBS and SHAM from 9-week-old PUUO and SHAM rats. J-L: Immunohistochemistry for COX-2 in the interstitial cells (filled arrows) of OBS, Non-OBS and SHAM from 15-week-old PUUO and SHAM rats. There is a strong labelling from obstructed kidneys ( $E$ and $K$ ) compared with Non-OBS (F and L) and SHAM kidneys ( $D$ and $\mathrm{J}$ ). study concurred that PUUO induced within 48 hours of life was associated with a marked urine osmolality reduction in the obstructed kidneys at 9 and 15 weeks after the onset of obstruction. The results of the present study support the view that neonatally-induced obstruction causes long-term and progressive reductions in renal function. ${ }^{16}$ Importantly, the results of the present study demonstrate that the severity of the partial obstruction is crucial in determining the impairment of the renal function.

In the present study, we found an increased COX-2 expression in the obstructed kidneys in response to PUUO. It has been demonstrated that several conditions could induce COX-2 expression, including dehydration, arginine vasopressin, and $\mathrm{NaCl}$ loading in the inner medulla (IM) of the kidney. ${ }^{12} \mathrm{~A}$ recent study revealed that COX-2 expression, but not COX-1 in the rat IM, was up-regulated by hyperosmolality and closely correlated with urine osmolality. ${ }^{17}$ In the current study, PUUO led to a marked decrease in urine osmolality. Thus the enhanced COX-2 expression in the obstructed kidneys induced by PUUO is independent of this change in urinary osmolality. The mechanisms involved in the COX-2 induction in response to 9 weeks and 15 weeks of PUUO were not directly addressed in the present study, but several possibilities exist. During several weeks after the onset of obstruction, the pressure in the urinary tract was highly elevated and this pressure increase may have mechanically stimulated interstitial cells and induced an increase in COX-2 expression. Consistent with this, it was recently demonstrated that the mechanical stretch can stimulate COX-2 in the bladder and vasculature. ${ }^{18}$ Increases in COX-2 expression may also result from inflammatory mediators in the kidney. Previous studies have shown that UUO lasting more than 96 hours in rats led to an intense infiltration of inflammatory cells in the renal interstitium. ${ }^{19}$ Moreover, as noted in a previous report, in the unilateral ureteral obstructed kidney the increased expression of COX-2 may provide an additional strong stimulus to synthesize large quantities of PGs. ${ }^{9}$ The large amounts of PGE2 produced may contribute to impaired medullary $\mathrm{NaCl}$ transport and urinary concentration in the obstructed kidney. It has been demonstrated that increased PGE2 synthesis in response to urinary tract obstruction may dysregulate renal AQPs and sodium transporters, which are crucial for the impaired urinary 


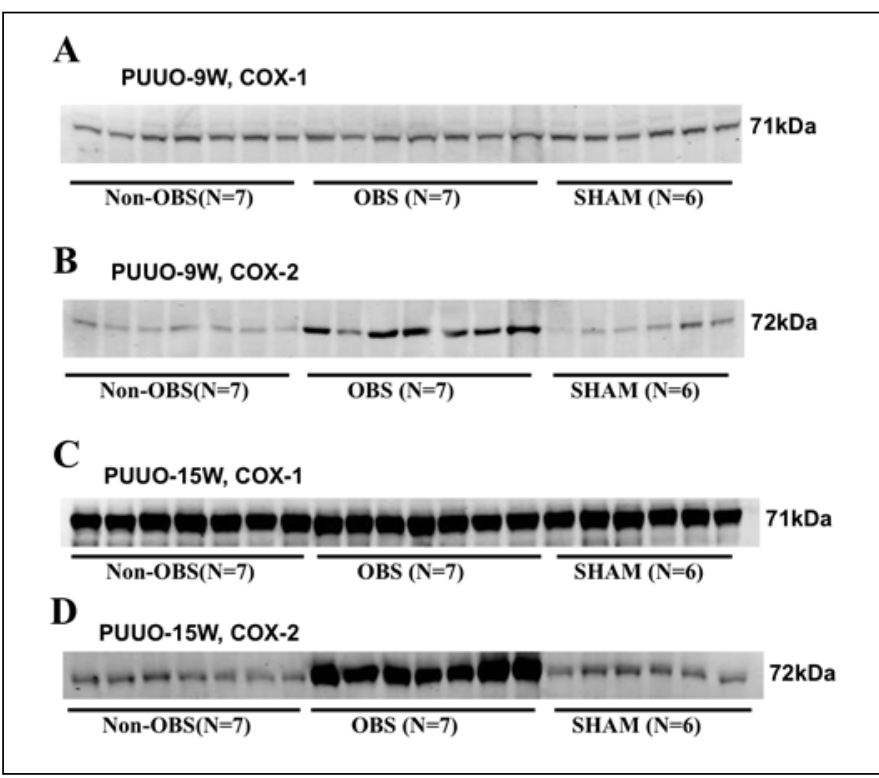

Fig. 2. PSemiquantitative immunoblotting of whole kidney protein samples from obstructed (OBS) and non-obstructed kidneys (Non-OBS) from PUU0-9 W and PUU0-15 W rats, and kidneys from matched sham-operated rats (SHAM).

A, C: Immunoblots were reacted with anti-COX-1, revealing a single band of approximately $71 \mathrm{kDa}$. Densitometry analysis revealed, COX-1 expression in the obstructed kidneys did not change in PUU0-9W (A) and PUU0-15W (C). B, D: Immunoblots were reacted with anti-COX-2, revealing a single band of approximately $72 \mathrm{kDa}$. Densitometry analysis revealed a marked increase in expression level of COX-2 expression in the obstructed kidneys in the OBS compared with Non-0BS and SHAM in PUUO-9W (B) and PUUO-15W (D).

concentration capacity in obstructive nephrogenic diabetes insipidus. ${ }^{12}$ In vitro studies have demonstrated that PGE2 suppresses $\mathrm{Na}+$ reabsorption in the IM collecting duct; this process involves the inhibition of $\mathrm{Na}+, \mathrm{K}+$-adenosine triphosphatase, which is reversed by COX blockade with indomethacin. ${ }^{20}$ The present study demonstrated that urinary sodium was increased from the obstructed kidneys at 9 and 15 weeks after the onset of obstruction; this is supported in previous findings. ${ }^{20}$

Not all investigated proteins were equally sensitive to obstruction. Thus COX-1 did not change during the conditions tested, which documents that the observed PUUOinduced changes were specific and not related to widespread necrosis or unspecific proteasomal degradation of all proteins. This is consistent with the other studies in $\mathrm{BUO}^{12}$ and UUO models. ${ }^{9}$

It is well-established that congenital ureteral obstruction is associated with the development of a pronounced interstitial inflammatory response, which subsequently leads to progressive renal interstitial fibrosis. ${ }^{1}$ Recently, it was demonstrated that the down-regulation of protein expression of major renal acid-base transporters is time/age dependent in response to PUUO,${ }^{14}$ but not in renal sodium transporters and aquaporins. ${ }^{6}$ The potential mechanisms responsible for dysregulation of the renal COX-2 may show a dynamic change with time. Thus, the observed changes at 9 and 15 weeks after the onset of obstruction may not reveal the immediate response to PUUO. This needs to be addressed in more detail in future experiments.

\section{Conclusion}

COX-2, not COX-1, in the obstructed kidney is upregulated in response to neonatally-induced PUUO. These changes were paralleled by increased urinary sodium and a significant reduction in the urine osmolality from the obstructed kidney, demonstrating a functional association between the molecular changes and the ability of the obstructed kidney to handle sodium and water. Thus, the study indicates that COX-2 may be an important factor contributing to the reduction in renal handling of sodium and water in response to PUUO. Importantly, selective COX-2 inhibition may represent a potential therapeutic method for impaired urinary concentration capacity in children with congenital pelvicureteral junction obstruction.

Competing interests: None declared.

This paper has been peer-reviewed.

\section{References}

1. Chevalier RL, Forbes MS, Thornhill BA. Ureteral obstruction as a model of renal interstitial fibrosis and obstructive nephropathy. Kidney Int 2009;75:1145-52. http://dx.doi.org/10.1038/ki.2009.86

2. Klahr S. Urinary tract obstruction: In: Schrier RW, editor. Disease of the kidney and urinary tract. 7th edition. Lippincott Williams \& Wilkins, Philadelphia, PA; 2011:757-87.

3. Li C, Wang W, Kwon TH, et al. Altered expression of major renal Na transporters in rats with unilateral ureteral obstruction. Am J Physiol Renal Physiol 2003;284:F155-66.

4. Li C, Wang W, Knepper MA, et al. Downregulation of renal aquaporins in response to unilateral ureteral obstruction. Am J Physiol Renal Physiol 2003;284:F1066-79.

5. Wen JG, Chen Y, Frokiaer J, et al. Experimental partial unilateral ureter obstruction. I. Pressure flow relationship in a rat model with mild and severe acute ureter obstruction. J Urol 1998;160:1567-71. http://dx.doi.org/10.1016/S0022-5 347(01)62614-4

6. Shi Y, Li C, Thomsen K, et al. Neonatal ureteral obstruction alters expression of renal sodium transporters and aquaporin water channels. Kidney Int 2004;66:203-15. http://dx.doi.org/10.1111/i.15231755.2004.00721.x

7. Harris RC, Breyer MD. Physiological regulation of cyclooxygenase-2 in the kidney. Am J Physiol Renal Physiol 2001;281:F1-11.

8. Parente L, Perretti M. Advances in the pathophysiology of constitutive and inducible cyclooxygenases: two enzymes in the spotlight. Biochem Pharmacol 2003;65:153-9. http://dx.doi.org/10.1016/ S0006-2952(02)01422-3

9. Chou SY, Cai H, Pai D, et al. Regional expression of cyclooxygenase isoforms in the rat kidney in complete unilateral ureteral obstruction. J Urol 2003;170:1403-8. http://dx.doi.org/10.1097/01. ju. 0000082964.24635 .15

10. Ozturk H, Ozdemir E, Otcu S, et al. Renal effects on a solitary kidney of specific inhibition of cyclooxygenase-2 after $24 \mathrm{~h}$ of complete ureteric obstruction in rats. Urol Res 2002;30:223-6. http://dx.doi. org/10.1007/s00240-002-0266-1

11. Cheng $X$, Zhang $H$, Lee $H L$, et al. Cyclooxygenase-2 inhibitor preserves medullary aquaporin-2 expression and prevents polyuria after ureteral obstruction. J Urol 2004;172:387-90. http://dx.doi org/10.1097/01.ju.0000143882.52960.ee 
12. Nørregaard $R$, Jensen $B L$, Li C, et al. COX-2 inhibition prevents downregulation of key renal water and sodium transport proteins in response to bilateral ureteral obstruction. Am J Physiol Renal Physiol 2005;289:F322-333. http://dx.doi.org/10.1152/aiprenal.00061.2005

13. Wen JG, Ringgaard $S$, Jørgensen $T M$, et al. Long-term effects of partial unilateral ureteral obstruction on renal hemodynamics and morphology in newborn rats: A magnetic resonance imaging study. Urol Res 2002;30:205-12. http://dx.doi.org/10.1007/s00240-002-0267-0

14. Wang G, Topcu SO, Ring T, et al. Age-dependent renal expression of acid-base transporters in neonatal ureter obstruction. Pediatr Nephrol 2009;24:1487-500. http://dx.doi.org/10.1007/s00467-009-1193-y

15. Topcu $S 0$, Pedersen $M$, Nørregaard $R$, et al. Candesartan prevents long-term impairment of renal function in response to neonatal partial unilateral ureteral obstruction. Am J Physiol Renal Physiol 2007;292:F73648. http://dx.doi.org/10.1152/aiprenal.00241.2006

16. Chevalier RL, Thornhill BA, Chang AY. Unilateral ureteral obstruction in neonatal rats leads to renal insufficiency in adulthood. Kidney Int 2000;58:1987-95. http://dx.doi.org/10.1111/j.15231755.2000.00371.x
17. Yang T, Schnermann JB, Briggs JP. Regulation of cyclooxygenase-2 expression in renal medulla by tonicity in vivo and in vitro. Am J Physiol 1999;277:F1-9.

18. Park JM, Yang T, Arend $\amalg$, et al. Obstruction stimulates COX-2 expression in bladder smooth muscle cells via increased mechanical stretch. Am J Physiol Renal Physiol 1999;276:F129-36.

19. Ricardo SD, Ding G, Eufemio $M$, et al. Antioxidant expression in experimental hydronephrosis: role of mechanical stretch and growth factors. Am J Physiol 1997;272:F789-98.

20. Kaij DM, Chase HS Jr, Eng JP, et al. Prostaglandin E2 inhibits Na-K-2Cl cotransport in medullary thick ascending limb cells. Am J Physiol 1996;271: (354-61.

Correspondence: Dr. Yi Zhang, Biological Cells Treatment Center, First Affiliated Hospital of Zhengzhou University, Henan, China. 450052; fax: +86 371 66295219; zzygy120@126.com 